\title{
American Board of Thoracic Surgery examination: Fewer graduates, more failures
}

\author{
Susan D. Moffatt-Bruce, MD, PhD, Patrick Ross, MD, PhD, and Thomas E. Williams, Jr, MD, PhD
}

Background: The American Board of Thoracic Surgery (ABTS) has noted a yearly decrease in the number of examination certificates being awarded, with only 93 certificates awarded in 2011. In 2003, the Accreditation Council for Graduate Medical Education required all programs to implement the 80-hour residency workweek. We hypothesized that this requirement has resulted in trainees being less capable of becoming successfully certified.

\begin{abstract}
Methods: We examined the ABTS board scores, both written and oral, from 2000 to 2011. We divided the interval into 2 periods: 2000 to 2005, representing the 6-year, pre-80-hour workweek, and 2006 to 2011, the 6-year period post-80-hour workweek implementation. We analyzed whether a significant difference would be present in the pass rate before and after the 80-hour workweek for both the written and the oral boards.

Results: An inflection point of examination failures was found that started in 2006, correlating with the first examination year the 80-hour workweek would have affected. The written examination failure rates increased from 2006 to 2009 but have since decreased. The actual percentage failing the written component was less than the percentage failing the oral examinations in both periods. The oral examination failure rates have continued to increase at an alarming rate.

Conclusions: An increase has occurred in the failure of the ABTS board examinations that has been significantly greater after implementation of the 80-hour workweek. The failure rate for the written examination was not as significant as that for the oral examination. Because we are now training fewer, and perhaps less successful, cardiothoracic surgeons, it is our duty to develop strategies to improve and promote innovation in the methods of training. (J Thorac Cardiovasc Surg 2014;147:1464-70)
\end{abstract}

It has previously been published that we can expect an imminent shortage of cardiothoracic surgeons as early as 2020. ${ }^{1,2}$ Cardiothoracic surgeons will continue to be of tremendous importance to all healthcare systems, because cardiovascular disease is likely to remain the leading cause of mortality and morbidity for the elderly, with about 600,000 people dying of heart disease in the United States every year. ${ }^{3}$ Similarly, thoracic surgeons will remain a vital part of all preventative and intervention strategies, with lung cancer the second most common type of cancer among both men and women. ${ }^{4}$ The applications for fellowship in the specialty of cardiothoracic surgery has decreased at an alarming rate. ${ }^{1}$ The concern we have is that, not only have fewer surgeons been training to become cardiothoracic surgeons, but also that fewer have actually been successful

From the Department of Surgery, Ohio State University Wexner Medical Center, Columbus, Ohio.

Disclosures: Authors have nothing to disclose with regard to commercial support.

Read at the 93rd Annual Meeting of The American Association for Thoracic Surgery, Minneapolis, Minnesota, May 4-8, 2013.

Received for publication April 28, 2013; revisions received Dec 23, 2013; accepted for publication Jan 2, 2014; available ahead of print Feb 9, 2014.

Address for reprints: Susan D. Moffatt-Bruce, MD, PhD, Department of Surgery, Ohio State University Wexner Medical Center, 130 Doan Hall, 410 W 10th Ave, Columbus, OH 43210 (E-mail: Susan.moffatt-bruce@osumc.edu).

$0022-5223 / \$ 36.00$

Copyright (C) 2014 by The American Association for Thoracic Surgery

http://dx.doi.org/10.1016/j.jtcvs.2014.01.003 once admitted to the residency training program. Since 2000, the American Board of Thoracic Surgery (ABTS) has awarded 1476 new certificates, averaging 123 annually. The number has decreased from 126 certificates in 2000 to 93 certificates in 2011.

The Accreditation Council for Graduate Medical Education required all training programs to implement the 80 -hour residency workweek in 2003 , thereby potentially affecting the cardiothoracic surgery graduates taking the 2006 board examinations. ${ }^{5}$ Early comparative studies indicated that the 80-hour resident workweek did not adversely affect or improve patient outcomes or resident education. .,7 $^{6}$ Concerns regarding outcomes, in particular, as they have become more publically reportable and scrutinized, has established a need for another review of the expectations of residents and attending surgeons. A tension now exists between the ability to learn to perform complex procedures, service "scut work," and the value of midlevel providers. ${ }^{8,9}$ These concerns will prevail as we strive to create safe hospitals, train competent physicians and surgeons, and preserve the sanctity of the physicianpatient relationship. ${ }^{10}$ The effects of the 80 -hour workweek on residency and fellowship training have been very real. ${ }^{11,12}$ Reducing the weekly hours translates into a 6- to 12-month reduction of in-hospital experience during a 5-year residency. ${ }^{11}$ Applied to a 2- or 3-year cardiothoracic surgery residency, 3 to 7 months of training can be lost. 


\section{Abbreviations and Acronyms \\ ABTS $=$ American Board of Thoracic Surgeons \\ $\mathrm{CABG}=$ coronary artery bypass grafting}

Most of this reduced time will correspond to night and weekend experience when residents would be more likely to see high acuity and urgent conditions and have a greater degree of independent assessment and patient treatment. We hypothesized that this reduction in experiential learning would affect the success rate of cardiothoracic surgery residents in completing their examinations. In particular, the oral examinations would be most affected, reflecting the inexperience of being first responders in cardiac or thoracic patient scenarios. We have reviewed the examination results of residents before and after the 80-hour work week implementation.

\section{METHODS}

We examined the ABTS board scores, both written and oral, for a 12-year period from 2000 through 2011. We divided this interval into 2 periods: 2000 through 2005, representing the examinees who would have taken the examination before the implementation of the 80-hour workweek, and 2006 through 2011, representing those who would have taken the certifying examinations after the implementation of the 80-hour workweek. We analyzed whether a significant difference was present in the overall pass rate between the 2 groups. Additionally, we analyzed the written and oral board pass rates for these 2 groups. Chi-square analysis was performed to compare the experimental groups.

\section{RESULTS \\ Reduction in Residency Applications Paralleled a Reduction in Cardiothoracic Surgery Residency Programs}

In 2006, 95 programs were offering cardiothoracic surgery training positions. By 2012, that number had decreased to 72 (Figure 1). Also, in 2006, 139 training positions were offered, but by 2012, only 102 training positions were offered. The applicant numbers have also decreased from 2006 to $2012 .{ }^{13}$ In 2006, there were 104 applicants and in 2012, only 78 applications for cardiothoracic surgery training positions.

\section{Number of Examination Certifications Awarded to Cardiothoracic Surgery Trainees has Declined During the Past Decade}

In 2000 , more than 120 certificates were successfully granted to eligible trainees by the ABTS. From 2000 to 2011, the number of candidates who successfully completed their training and were awarded examination certification had decreased to 92 (Figure 2). From 2000 to 2006, an oscillating pattern was seen, with $\leq 160$ examination certifications awarded. The inflection point was 2006; since then, a steady decline has occurred in successful cardiothoracic surgery examination certification. The ABTS examination scores from 2000 to 2011 are listed in Table 1. The first year that the examination results would have been affected by the 2003 implementation of the 80-hour workweek rules was 2006.

\section{Oral Versus Written Examination Success was Notably Different After 2006}

The examination year of 2006 was the first year when cardiothoracic surgery residents who had started programs in 2003 could take the board examinations. The results showed a trend toward increased examination failures in 2006 (Table 1). The written examination failure rate increased from 2006 to 2009 but has recently decreased to about the same level seen in 2005 (Figure 3). This initial increase in the written examination failure rate might have reflected the disruption of the new duty hour expectations that the trainees ultimately learned to accommodate. Only in 2003 did the written examination failure rate exceed the oral failure rate. From 2000 and 2005, 903 candidates took the written examination, with a $10.6 \% \pm 3.7 \%$ failure rate. From 2006 to 2011, 672 candidates took the written examination, with a failure rate of $17.4 \% \pm 3.4 \%$, significantly greater during for the latter period, despite eventually achieving success rates similar to those of the 2005 examination year $(P<.01$; Figure 4$)$.

The oral examination failure rate started to increase in 2006 and has continued to increase (Figure 3). From 2000 to 2005,955 candidates took the oral examination, with a failure rate of $14.4 \% \pm 4.1 \%$. The chi-square statistic was $5.92(P<.02)$. From 2006 and 2011, 693 candidates took the oral examination, with a $28.1 \% \pm 4.6 \%$ failure rate, significantly greater $(P<.001$; Figure 5$)$.

\section{DISCUSSION}

We have previously presented the concern that the number of trained cardiothoracic surgeons will not be sufficient to care for the increasing American population. ${ }^{1}$ The timing of that shortfall has been projected to occur as soon as 2020 - only 6 years away. ${ }^{1,2}$ The reasons for the decrease in the number of applicants have included personal choices, lifestyle, remuneration, and financial constraints. ${ }^{1,2,14}$

The present study has allowed us to further the discussion on the eventual shortage of surgeons as a result of residents not passing the qualifying examinations. We hypothesized that the 80-hour workweek Accreditation Council for Graduate Medical Education requirement has potentially resulted in less successful graduates because of less experiential learning. From 2000 to 2011, the number of candidates who successfully completed their training and were awarded examination certification decreased to 92 . Additional analysis revealed that from 2006 to 2011, 672 candidates took the written examination, with a failure rate of $17.4 \%$. After implementation of the 80 -hour 


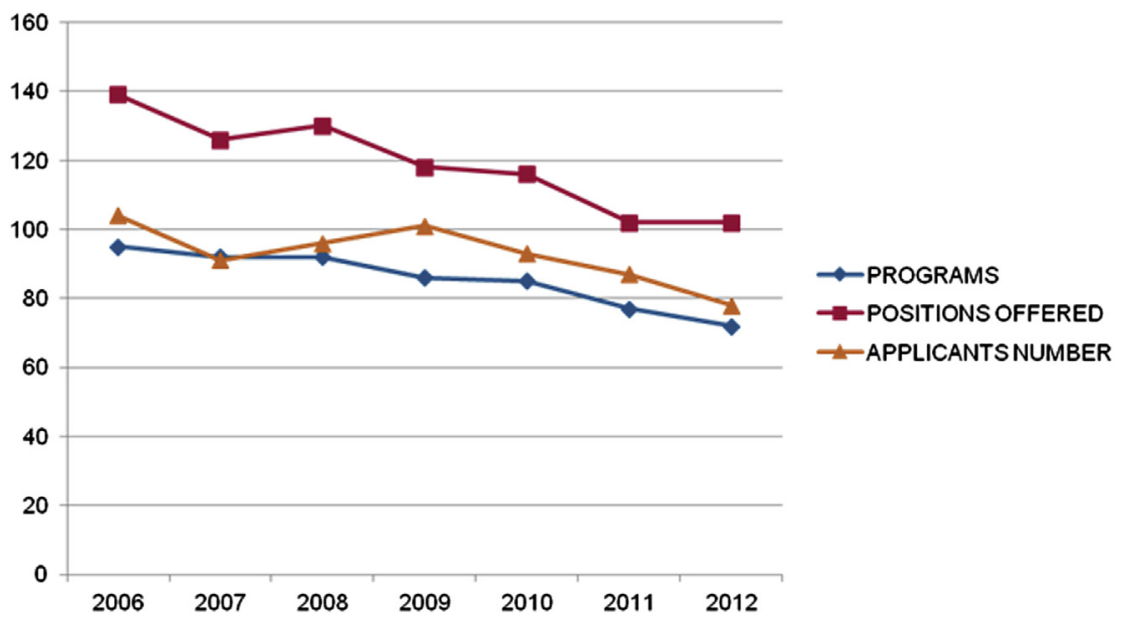

FIGURE 1. Since 2006, a reduction in applications for cardiothoracic surgery training has been paralleled by a reduction in programs offering training. From 2006 through 2012, at no time did the number of applicants match the number of available training positions.

workweek, 693 candidates took the oral examination, with a $28.1 \%$ failure rate. Additionally, we must acknowledge that compounding this reduction in workweek hours was the important change in the examination format requiring the candidate to pass both the thoracic and the cardiac components. Therefore, many possible mechanisms are at play and are likely interdependent.

Connors and colleagues ${ }^{7}$ revealed that the overall volume of thoracic surgery cases was not significantly affected by the 80-hour workweek restriction but that the total number of cardiac surgery cases logged was substantially less. This was likely compounded because in 2007 the ABTS changed the format of the examination to require passing both the cardiac and thoracic components of the examination. Caution must therefore be taken, with a wider adoption of the designated thoracic and cardiac training tracks because the examination will require a thorough understanding of both. Our results have revealed that the written examination success rate recovered after the initial disruption of the new 80-hour work week expectations, indicating that residents can read enough to address the written examination; the same is unlikely to be true for the oral examination.

Stephens and colleagues ${ }^{8}$ surveyed the perceptions and expectations of cardiothoracic residents and attending physicians. Their findings revealed a distinct disconnect between the trainee and trainer. The attending physicians revealed that for most low-complexity cases, the residents were sufficiently prepared; however, this was not true for the highly complex cases. This contrasted with the residents' perception that they needed more experiential time and that increased scrutiny around outcomes had adversely affected training. Additionally, the residents had

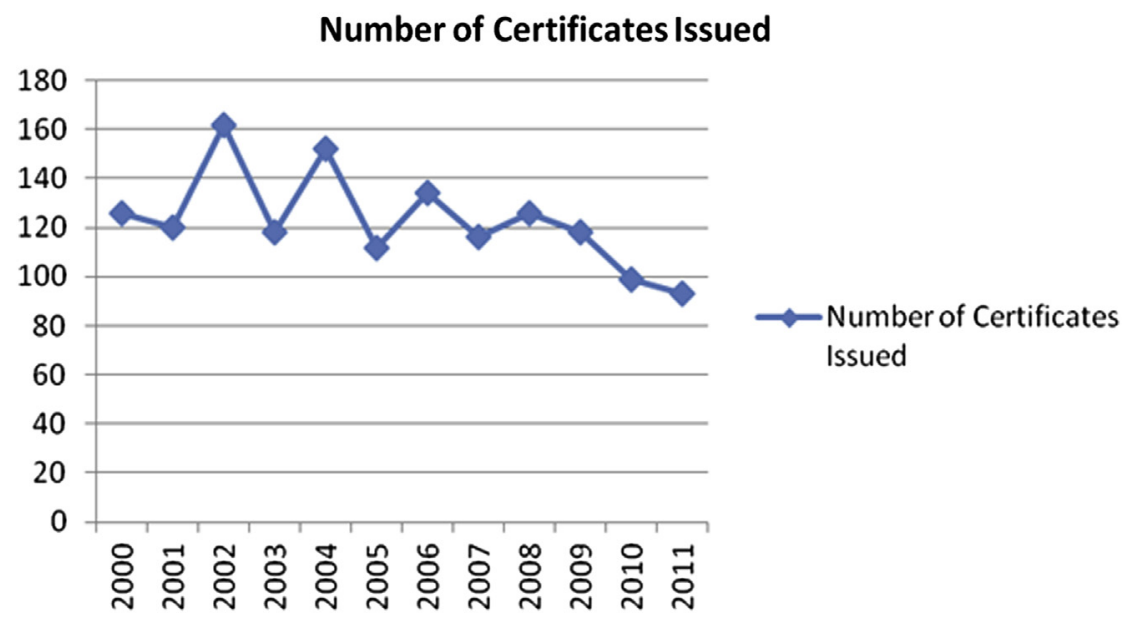

FIGURE 2. The number of successful examination certifications in cardiothoracic surgery decreased to only 92 in 2011 . From 2000 to 2006 , an oscillating pattern was seen, with $\leq 160$ examination certifications awarded. The inflection point was 2006 ; since then, a steady decline has occurred in the successful examination certification process. 
TABLE 1. American Board of Thoracic Surgery examination scores, 2000 through 2011

\begin{tabular}{cccccccc}
\hline & \multicolumn{3}{c}{ Written examination } & & \multicolumn{3}{c}{ Oral examination } \\
\cline { 2 - 4 } \cline { 6 - 7 } Year & Total & Passed & Failed & & Total & Passed & Failed \\
\hline 2000 & 149 & 127 & $22(15.0)$ & & 150 & 116 & $34(22.7)$ \\
2001 & 132 & 120 & $12(9.0)$ & & 178 & 155 & $23(13.0)$ \\
2002 & 170 & 162 & $8(4.7)$ & & 155 & 133 & $22(14.0)$ \\
2003 & 155 & 133 & $22(14.0)$ & & 164 & 146 & $18(11.0)$ \\
2004 & 166 & 153 & $13(8.0)$ & & 144 & 128 & $16(11.0)$ \\
2005 & 131 & 113 & $18(14.0)$ & & 164 & 139 & $25(15.0)$ \\
2006 & 160 & 138 & $22(14.0)$ & & 177 & 142 & $35(20.0)$ \\
2007 & 160 & 133 & $27(16.9)$ & & 164 & 116 & $48(29.0)$ \\
2008 & 137 & 111 & $26(19.0)$ & & 174 & 125 & $49(28.0)$ \\
2009 & 127 & 98 & $29(22.8)$ & & 161 & 118 & $43(26.7)$ \\
2010 & 116 & 94 & $22(19.0)$ & & 147 & 99 & $48(32.7)$ \\
2011 & 114 & 99 & $15(13.2)$ & & 141 & 93 & $48(34.0)$ \\
\hline
\end{tabular}

Data presented as $n(\%)$.

a perception that they needed to be in the operating room most of the time, not participating in pre- and postoperative care, to not miss the opportunity to gain competency. Our findings that the oral board examination failure rates have continued to increase support the idea that residents are not gaining knowledge or the nuances of direct patient care. A tension clearly exists between "hands on" clinical care experience and operating expertise development.

Although the first phase of the duty hour requirements for all US residency programs by the Accreditation Council for Graduate Medical Education was implemented in 2003, the second set of duty hour requirements took effect in 2011. The results of these changes are now being studied and presented. ${ }^{9,10,15-18}$ Of concern is not the effect on education, but, rather, on a previously not seen increase in medical errors. This contradicts some of the impetus of the initial introduction of the work hour restrictions, in which fatigue was believed to affect the cognitive and motor skills of the residents. ${ }^{18,19}$ It would appear that clinical competence, allowing for safe patient care, might be compromised because sufficient time spent acquiring knowledge and proficiency is not possible. ${ }^{17}$ Our results of a reduced ability to correctly address the oral examination questions for both the clinical and the technical care of cardiothoracic surgery patients might reflect these findings that are now coming to light. Recognizing these challenges, educators must engage in new training modalities and evaluation techniques. Simulation will provide some additional training but might not be sufficient, or able, to replace operative experience. The Thoracic Surgery Milestone Project, which is currently in a pilot phase, will undoubtedly address the challenges. ${ }^{20}$ This outcomes-based training and evaluation of cardiothoracic residents allows for specific behaviors, attributes, or outcomes to be demonstrated by residents by a particular point during the residency. As this project is implemented, careful measurement of resident certification success will gauge the adequacy of this novel training and evaluation process.

The restrictions placed on American trainees are not as severe as those in Europe, where the work hours for

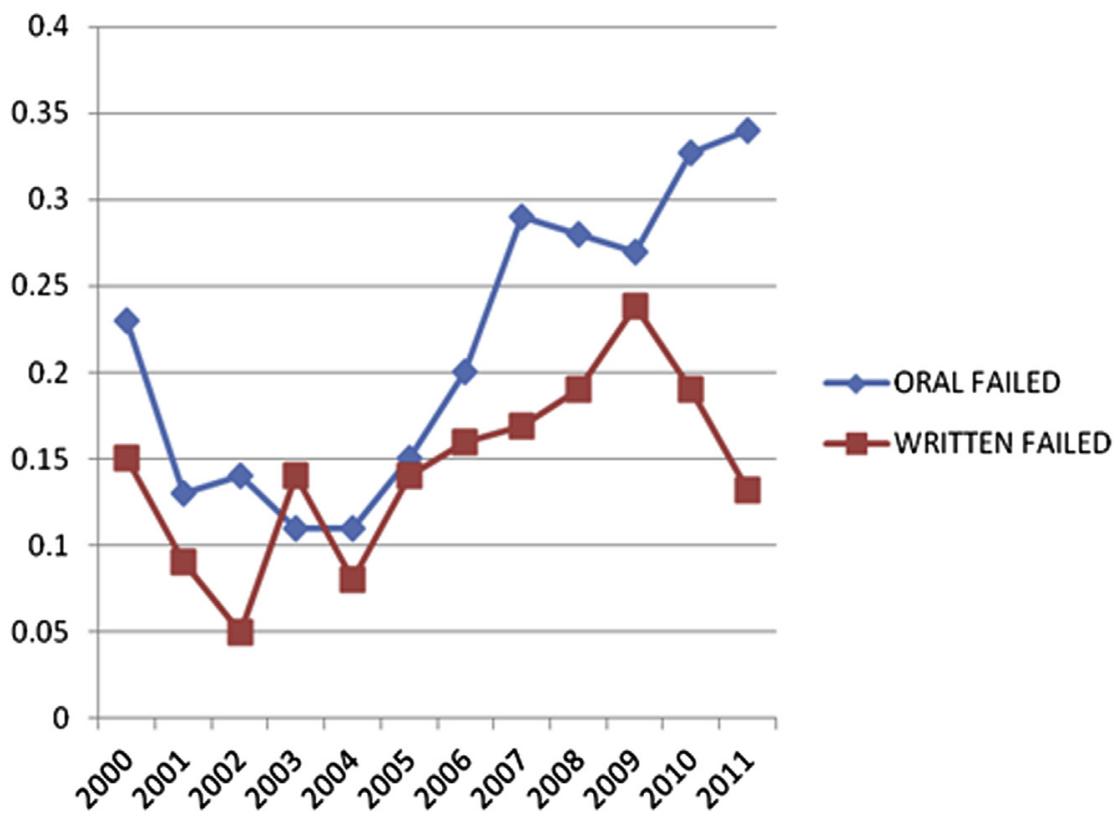

FIGURE 3. The success rate for oral versus written examinations was notably different after 2006. The written examination failure rate increased from 2006 to 2009 but has recently decreased to about the same level as in 2005. The oral examination failure rate started to increase in 2006 and has continued to increase. Only in 2003 did the written examination failure rate exceed the oral examination failure rate. 


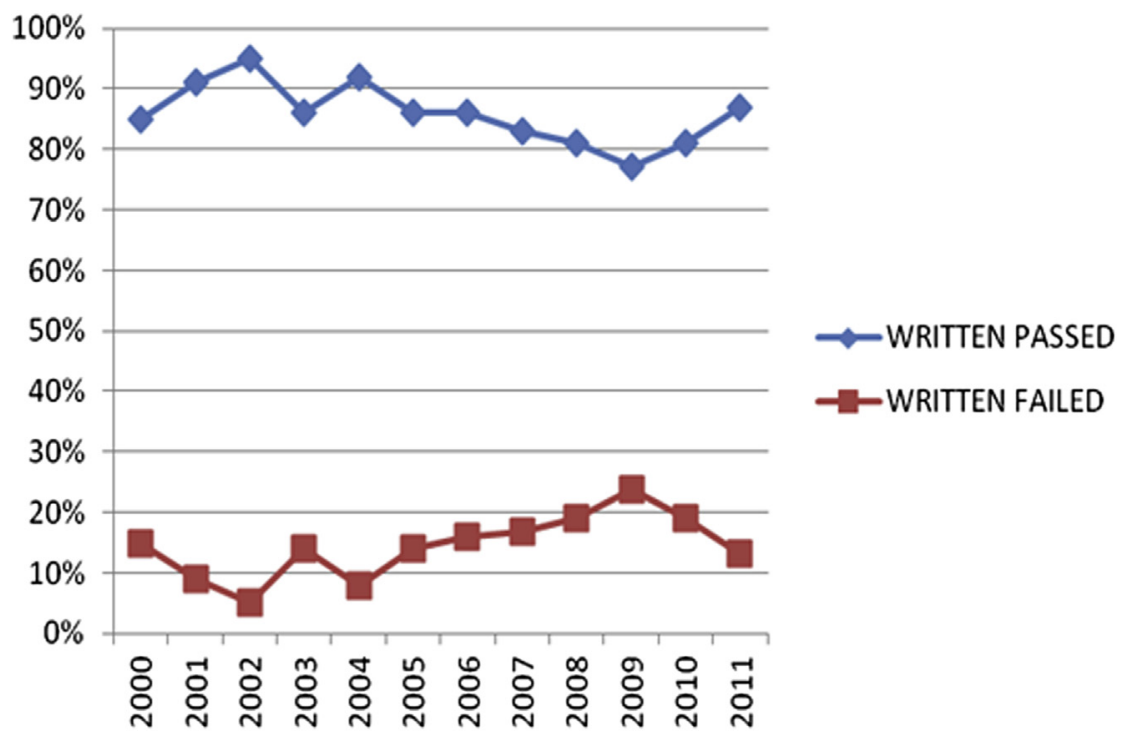

FIGURE 4. The success rate for the written examination differed in the 2 periods studied. From 2000 and 2005 , 903 candidates took the written examination, with a $10.6 \% \pm 3.7 \%$ failure rate. From 2006 to 2011,672 candidates took the written examination, with a $17.4 \% \pm 3.4 \%$ failure rate, significantly greater during the latter period, despite eventually reaching the success rates of the 2005 examination year $(P<.01)$.

physicians in training have been limited to 48 hours. $^{12,19,21,22}$ European trainees have also been reporting that they believe their operative experience has been much reduced; however, to date, neither the examination success rates nor novel strategies to address these challenges have been reported in published studies. ${ }^{21}$

\section{CONCLUSIONS}

The urgency of the shortage of cardiothoracic surgeons within the next decade, coupled with the additional work hour restrictions, has resulted in fewer, less capable residents, who have not been successfully certified owing to a reduction in experiential and first responder experience. Improved experiential education is therefore urgently needed because of the increasing failure rate for cardiothoracic surgery examinations. As we develop training for this generation of residents, we must continue to focus on the outcomes and emphasize clinical and technical ability, allowing residents to train to defined competencies, rather than for a specific training duration.

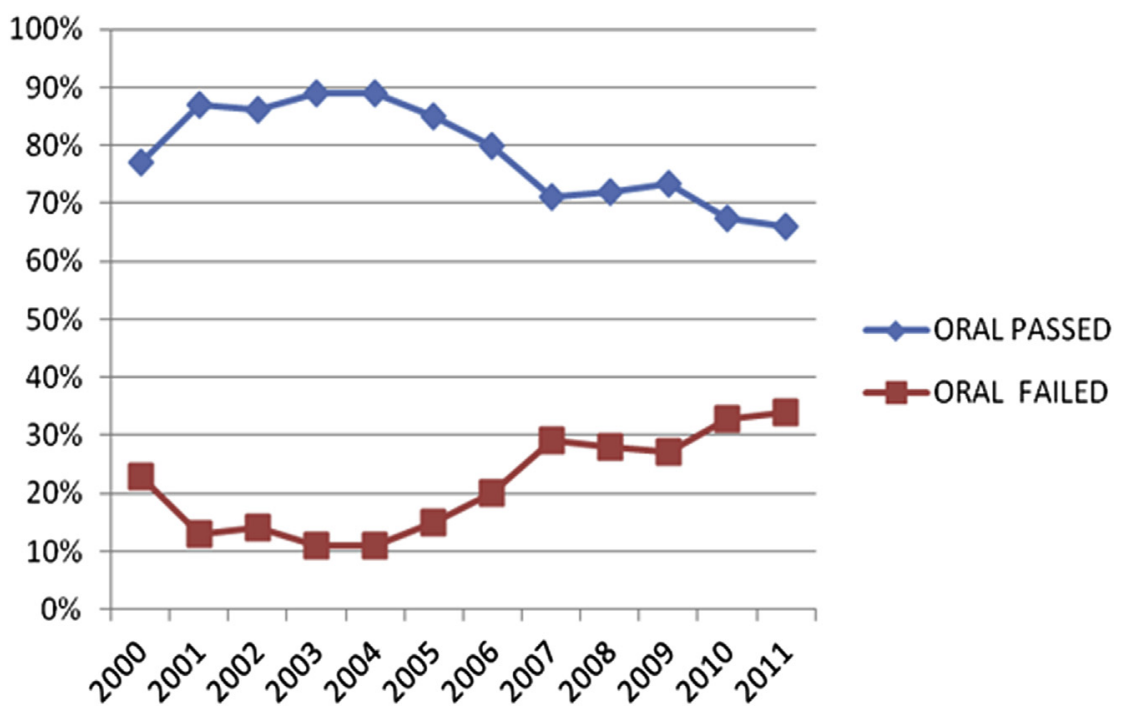

FIGURE 5. American Board of Thoracic Surgery oral scores for 2000 to 2011. From 2000 to 2005,955 candidates took the oral examination, with a failure rate $14.4 \% \pm 4.1 \%$. The chi-square statistic was $5.92(P<.02)$. From 2006 to 2011,693 candidates took the oral examination, with a $28.1 \% \pm 4.6 \%$ failure rate, a significantly greater rate $(P<.001)$. 


\section{References}

1. Williams TE Jr, Sun B, Ross P Jr, Thomas AM. A formidable task: population analysis predicts a deficit of 2,000 cardiothoracic surgeons by 2030. J Thorac Cardiovasc Surg. 2010;139:835-40.

2. Grover A, Gorman K, Dall TM, Jonas R, Lytle B, Shemin R, et al. Shortage of cardiothoracic surgeons is likely by 2020. Circulation. 2009;108:488-94.

3. Department for Health and Human Services, Centers for Disease Control. Heart disease. Available at: http://www.cdc.gov/heartdisease/facts.htm. Accessed March 19, 2013.

4. Department for Health and Human Services, Centers for Disease Control. Cancer. Available at: http://www.cdc.gov/cancer/dcpc/data/women.htm. Accessed March 19, 2013.

5. Accreditation Council for Graduate Medical Education. 2002-2003 Annual report http://www.acgme.org/acgmeweb/About/AnnualReport.aspx. Accessed February 13, 2013.

6. De Virgilio C, Yaghoubian A, Lewis RJ, Stabile BE, Putnam BA. The 80 hour resident workweek does not adversely affect patient outcomes or resident education. Curr Surg. 2006;63:435-9.

7. Connors RC, Doty JR, Bull DA, May HT, Fullerton DA, Robbins RC. Effect of work-hour restriction on operative experience in cardiothoracic surgical residency training. J Thorac Cardiovasc Surg. 2009;137:710-3.

8. Stephens EH, Cornwell LD, Simpson KH, Chu D, Coselli JS, Holman WL, et al. Perceptions and expectations of cardiothoracic residents and attending surgeons. J Surg Res. 2012;177:45-52.

9. Drolet BC, Khokhar MT, Fischer SA. The 2011 duty-hour requirements-a survey of residency program directors. N Engl J Med. 2013;368:694-7.

10. Rosenbaum L, Lamas D. Residents' duty hours - towards an empirical narrative. N Engl J Med. 2012;367:2044-9.

11. Lewis FR, Klingensmith ME. Issues in general surgery residency training 2012. Ann Surg. 2012;256:553-9.

12. Axelrod L, Shah DJ, Jena AB. The European working time directive: an uncontrolled experiment in medical care and education. JAMA. 2013;309: 447-501.

13. The Match: National Resident Matching Program. Available at: http://www. nrmp.org/. Accessed March 1, 2013

14. Cooper RA. It's time to address the problem of physician shortage: graduate medical education is the key. Ann Surg. 2007;246:527-34.

15. Sen S, Kranzler HR, Didwania AK, Schwartz AC, Amarnath S, Kolars JC, et al. Effects of the 2011 duty hour reforms on interns and their patients. JAMA Intern Med. 2013;173:657-63.

16. Desai SV, Feldman L, Brown L, Dezube R, Yeh HC, Punjabi N, et al. Effect of the 2011 vs 2003 duty hour regulation—compliant models on sleep duration, trainee education and continuity of patient care among internal medicine house staff. JAMA Intern Med. 2013;173:645-55.

17. Pellegrini VD. Ten thousand hours to patient safety, sooner or later. Acad Med. 2012;87:164-7.

18. Lee DY, Myers EZ, Rehmani S, Wexelman BA, Ross RE, Belsley SS, et al. Surgical resident's perception of the 16-hour work day restriction: concern for negative impact on resident education and patient care. J Am Coll Surg. 2012; 215:868-77.

19. Crosson RJ, Leu J, Roemer BM, Ross MN. Gaps in residency training should be addressed to better prepare doctors for a twenty-first-century delivery system. Health Affairs. 2011;11:2142-8.

20. The Next Accreditation System. Accreditation Council for Graduate Medical Education. Available at: http://www.tsda.org/wp-content/uploads/2013/02/TSDAGeneral-Session.Milestones-Update.Jan-203.pdf. Accessed March 1, 2013.

21. Iglehart JK, Baron RB. Ensuring physicians competence-is maintenance of certification the answer? N Engl J Med. 2012;367:2543-9.

22. Parsons BA, Blencowe NS, Hollowood AD, Grant JR. Surgical training: the impact of changes in curriculum and experience. J Surg Educ. 2011;68:44-51.

\section{Discussion}

Dr Richard J. Shemin (Los Angeles, Calif). My disclosure is that I am the vice-chair of the American Board of Thoracic Surgery.

Dr Moffatt-Bruce, you and your co-investigators have studied an area of serious concern for all those involved in thoracic surgery education, that is, that the failure rate for the American Board of Thoracic Surgery examinations has risen at an alarming rate during the past several years. You have tracked the failure rates in both the ABTS qualifying examination, that is, the written examination, and the certifying examination, the oral examination, for the period from 2000 to 2011 . You observed that this failure rate increased in 2006 as an inflection point, and you have correlated this with the initiation of the reduction in work hours for resident training since 2003.

The failure rate for the written examination peaked in 2009 at $23 \%$ and, without any intervention, has actually decreased to $13 \%$ in 2011 - the level before the resident work hour restriction. The oral examination, however, had a failure rate of $23 \%$ in 2000 , ranged from $11 \%$ to $15 \%$ until 2005 , and has reached an alarming rate of $33 \%$, and we do not know how high or whether it will decrease without any further intervention.

Surely, the work hour restrictions and decreased experiential learning cannot be the predominant reasons for these results. The trend must be multifactorial. However, I will not deny that the restricted work hours and reduced resident experience and responsibility for patient care are important contributors. There are resident factors, program and curricular factors, and, possibly, factors even related to the format or how we administer the examination.

That we have contracted to only 72 programs and only had 78 applicants in 2012 for 102 places is a major concern, and, really, the selectiveness of our residents has suffered greatly. Clearly, we still have very qualified residents, but we also know that residents have matched to programs who, possibly, would not have matched in a more competitive environment. The resident factors also include study habits and the use of the extra time outside the hospital to actually use that time for additional study.

As educators, we have not had a uniform adoption of a robust curriculum and a rigorous evaluation process to document the competency of our residents before we sign off that they are ready and prepared for independent practice and to enter the examination process. We need to ensure that the residents have a logical thought process about all thoracic diseases so that they can evaluate patients, conduct an operation, and also manage postoperative care and follow-up. For those of us who give the examination, it is absolutely amazing that those who have already passed the written examination cannot sit in front of an oral examiner and pass the oral examination scenarios.

The ABTS in 2007 changed its examination format. We have gone to 12 seven-minute scenarios: 6 cardiac and 6 thoracic surgery. In addition, all the examiners meet without the examinee after the examination to ensure fairness in grading the residents. In addition, it is required that the resident pass both the cardiac and the thoracic components. The tracking of residents can be a detriment, although we have not been able to prove that the tracking or placement in a thoracic versus a cardiac track has been a reason for failure. Recent data from the ABTS have suggested that those training in a 3-year program have scored better than those in a 2-year program, attesting to your idea that experiential learning is important to pass any of these scenarios. I also agree that we hope that the activities of the ABTS in having a standard curriculum and of the Joint Council in putting together a very robust curriculum with the Thoracic Surgery Directors 
Association and other partners, such as the Thoracic Surgery Residents Association, ABTS, and Society of Thoracic Surgeons, will quickly reverse this trend.

I have 1 question for you. You have alluded to a method to better prepare our residents in competency training. How would you suggest we would be able to do that, and if we adopt the milestones and if a resident is not competent for graduation, we certainly do not have the funding for graduate education to increase their length of training. So I would be interested in your comments in that area.

Dr Moffatt-Bruce. Thank you very much for those comments and the clarifications around some of the strategies currently.

About training to competency, to which we are fortunate to be, I am one of the pilots in that initiative, I think a very poignant tension will be developed to ensure that the residents proceed in a competent manner that is timely and financially responsible. I do not think that we have determined those failure modes to date, but I think it is the responsibility of those groups performing this in the pilot to develop those strategies. I know in our own institution where we are piloting this, we actually evaluate the competencies of our residents as a group, all the faculty together, so that we, first of all, can understand what it means to be competent and to be competency based, and then how we will remediate and what does that remediation look like, and how does that affect us financially?

I do not think we have the answers, but I would put it to the pilots to bring those lessons learned so that we can develop a robust program.

Dr Shemin. We are 1 year away before universal implementation of milestones, so how have you done this assessment of the residents?

Dr Moffatt-Bruce. We, as a training program, have participated in the pilot to date, but it has been challenging. I think we have learned a lot, because everybody's idea of competency is a little bit different. However, when you standardize it and do it as a group of assessors, I think it has been much more successful. I think the timing might be a little bit challenging to develop those failure modes of this process. Therefore, I would say that the recommendation of this pilot should probably be reevaluated and the implementation timing carefully evaluated.

Dr Thoralf Sundt (Boston, Mass). Do we know how many individuals fail the oral examination, because they failed either the cardiac side or the thoracic side?

Dr Moffatt-Bruce. I do not have those data but that would be a very important part to study. As a whole and speaking to the way we need to pass both, changes must ultimately be implemented as a group approach.

Dr Edward D. Verrier (Seattle, Wash). Just a quick comment. I think it is important to know that all the societies met a number of years ago to discuss this and that this spring we will roll out a completely new content management system for the curriculum, as well as a completely new curriculum and a learning management tool that will help track all these issues related to competency and related to the milestones. So, I just think it is very important to recognize that these issues have been on the table, they have been very carefully considered at the Board level and societal level and by some of the other organizations committed to education, and we will see significant transitions during the next year.

Dr Teresa Kieser (Calgary, Canada). Thank you for your excellent presentation. I think a key point here is that the number of applicants applying has decreased. In Canada, $>50 \%$ of the medical school graduates are women. Is this similar in the United States and perhaps women are not choosing this as a profession?

Dr Moffatt-Bruce. That is a very interesting question. I trained in America and in Canada, and I think as a woman, there are some challenges, but I do not think that it is the only challenge. As we study the new curriculum, to Dr Verrier's point, I think that the curriculum will become much more attractive to everybody. I think setting up experiences early on in the medical students' curriculum and in the medical students' environment will entice them to see that this really is a great career choice; that this is the way of the future, and that the need is going to be very real. We have to set the burning platform for everyone, and we can do that fairly easy by a joint effort among our various societies.

Dr Kieser. Thank you. 